\title{
Fetal Brain Development in Diabetic Guinea Pigs
}

\author{
JACQUES SAINTONGE(35) AND RAYMONDE CÔTÉ \\ Department of Pediatrics, Maisonneuve-Rosemont Hospital, Research Center, University of Montreal, School of \\ Medicine, Montreal, Quebec, Canada
}

\begin{abstract}
Summary
Fetal brain development was investigated near term in guinea pigs rendered diabetic with streptozotocin. The liver and the placenta were used as reference organs. Compared to controls, those fetuses from diabetic animals had normal cerebrum and cerebellum weights, but higher liver and placenta weights in relation to fetal weights. Although liver and placenta cell number (DNA content) was unchanged, it was significantly increased in the fetal cerebrum and cerebellum of diabetics. Although the tissue protein concentration was decreased in the liver and the placenta, it was unchanged and even increased in the cerebrum and cerebellum, respectively. The concentration of myelin (cerebroside-sulfatide) was unchanged in the cerebrum, but it was increased in the cerebellum of diabetic animals.

These data suggest that diabetes has a growth-promoting effect on the fetal brain cell number. Furthermore, differences in the protein content between fetal organs may reflect abnormalities in protein metabolism which do not affect the brain during diabetic pregnancies.
\end{abstract}

Textbooks of pediatrics and neonatology have repeatedly reported low brain weights in relation to body weights in macrosomic babies of diabetic mothers $(2,11,24,27)$. Gruenwald (14) has reported that the rate of growth of human fetal brain is diminished in diabetic pregnancies past 30 weeks of gestation. Decreased fetal brain weight in diabetic pregnancies has also been reported by Driscoll et al. (10) suggesting that maternal diabetes may interfere with fetal brain development.

In a recent study, a decreased placental transfer of amino acids to the fetus was found in diabetic guinea pigs (22). Consequently, diabetic pregnancy has been proposed as a new model of fetal malnutrition (23). While it has been shown that those parameters such as brain weight, cell number, protein content, and myelination were affected in situations of fetal malnutrition $(3,6,12$, $29,30)$ these characteristics of fetal brain development have not been investigated in diabetic pregnancies.

The goal of this study was to investigate fetal brain development during diabetic pregnancies, with regard to cerebral and cerebellar DNA, protein content, and myelination (cerebrosidesulfatide content). In order to detect any specific effects of diabetes on brain development, other organs such as the liver and placenta were also examined. The guinea pig was selected as the model in view of its brain maturity at birth which approaches the human situation more than other species $(1,5,8,9)$.

Female guinea pigs of the Hartley strain were fed a standard diet (guinea pig chow, Ralston Purina), with free access to water, and were maintained under normal laboratory conditions. Because insulin-induced hypoglycemia potentiates the diabetogenic activity of streptozotocin in this species $(4,15,20)$, the animals were given streptozotocin $(150 \mathrm{mg} / \mathrm{kg}$ ) IV (diabetic animals) or an equivalent amount of a saline solution (control animals) 90 min after one IV injection of 15 units of crystalline insulin.
After mating, day 1 of gestation was determined by the presence of spermatozoa in the vaginal smear, at which time the animals were isolated in separate cages.

Oral glucose tolerance tests were performed on days 10,30 , and 50 of gestation by force feeding the animals with a $25 \%$ glucose solution, $2 \mathrm{~g} / \mathrm{kg}$, after $18 \mathrm{~h}$ of fasting. Blood samples were obtained by puncture of ear capillaries and serum glucose levels were determined by the glucose oxidase technique (Beckman automatic glucose analyzer).

Near term (day 60 of gestation), an arterial blood sample was withdrawn for blood gases determination and the animals were sacrificed with an overdose of pentobarbital (Nembutal). A laparotomy was immediately performed in order to observe fetal gasping to ensure that all fetuses of the litter were alive. After a few minutes, fetuses and placentas were removed from the uterus. Placenta, cerebrum (including the cerebral hemispheres and the brain stem), cerebellum, and liver were removed, weighed, and homogenized in 4 volumes of distilled water.

DNA and proteins were precipitated with trichloroacetic acid from the same aliquot of homogenate, and they were separated according to the technique of Schneider (25) using highly polarized DNA of veal thymus as standard. Proteins were estimated according to a modified method of Bradford (26). Cerebroside and sulfatide were extracted as reported by Folch et al. (13), separated by thin layer chromatography on silica gel precoated aluminum plates, and after elution (7) quantified by a spectrophotometric technique using anthrone (18).

Analysis of results. The statistical significance of differences in mean values for both groups was determined using Student's $t$ test. Simple linear regression equations were calculated for different variables. The statistical significance of each regression coefficient and the linearity of each regression were investigated by analysis of variance. Differences in regression coefficient values were determined with a Student's $t$ test comparing population slopes (31).

\section{RESULTS}

Seven control animals ( 22 fetuses) and 10 diabetic animals ( 33 fetuses) were studied near term (day 60 of gestation). Gestational duration is 65 to 67 days in the guinea pig. All animals had normal arterial blood gases: $\mathrm{pH}, 7.48 \pm 0.01$ (SEM); $\mathrm{PCO}_{2}, 35 \pm$ $1 \mathrm{~mm} \mathrm{Hg} ; \mathrm{PO}_{2}, 76.5 \pm 3.2 \mathrm{~mm} \mathrm{Hg} ; \mathrm{HCO}_{3}^{-}, 25.5 \pm 0.6 \mathrm{meq} /$ liter; $\mathrm{O}_{2}$ saturation, $95.3 \pm 1 \%$. No differences in the acid-base status or in the arterial oxygenation were observed between control and diabetic animals. Compared to the controls, streptozotocin-treated animals were glucose intolerant during gestation as reflected by their glucose tolerance tests (Table 1).

Although fetal weight ranged from 43 to $94 \mathrm{~g}$, no differences were observed in the mean values of fetal weight between the two groups: $74.8 \pm 2.4 \mathrm{~g}$ in the controls versus $72.8 \pm 1.7 \mathrm{~g}$ in the diabetic animals (mean \pm SEM).

Cerebrum values. No significant differences were found between the two groups with regard to cerebral weight, protein, and 
FETAL DIABETIC GUINEA PIGS

Table 1. Results of glucose tolerance tests during gestation*

\begin{tabular}{|c|c|c|c|c|c|c|c|}
\hline & \multicolumn{7}{|c|}{ Serum glucose $(\mathrm{mg} / 100 \mathrm{ml})$} \\
\hline & $0 \min$ & $30 \mathrm{~min}$ & $60 \mathrm{~min}$ & $90 \mathrm{~min}$ & $120 \mathrm{~min}$ & $150 \mathrm{~min}$ & $180 \mathrm{~min}$ \\
\hline Control $(n=7)$ & $88 \pm 7$ & $160 \pm 14$ & $214 \pm 19$ & $231 \pm 21$ & $198 \pm 20$ & $153 \pm 17$ & $122 \pm 11$ \\
\hline Diabetic $(n=10)$ & $117 \pm 12$ & $218 \pm 15$ & $279 \pm 18$ & $302 \pm 19$ & $284 \pm 17$ & $250 \pm 19$ & $215 \pm 20$ \\
\hline$P$ & NS & $<0.01$ & $<0.025$ & $<0.02$ & $<0.005$ & $<0.001$ & $<0.001$ \\
\hline
\end{tabular}

* Each control and streptozotocin-treated animal was studied three times during gestation. Values are mean \pm SEM. NS, not significant.

cerebroside-sulfatide content (Table 2). However, cerebrum DNA content was increased $(P<0.001)$ in the fetuses of diabetic animals.

Cerebellum values. Although cerebellum weight, protein, and cerebroside-sulfatide values were comparable in both groups, the protein content was increased $(P<0.05)$, when expressed per tissue weight, but it was decreased $(P<0.001)$ when expressed per number of cells (DNA) in diabetic animals (Table 3 ). The cerebroside-sulfatide content per $\mathrm{g}$ of cerebellum was also increased $(P<0.05)$ in diabetic animals. As found in the cerebrum, cell number (DNA content) was increased $(P<0.001)$ in the fetal cerebellum of diabetic animals.

Liver and placenta values. No significant differences were observed in the weight or in the DNA content of the liver and the placenta between the two groups (Table 4). However, liver weight, when reported as a percentage of fetal weight, was increased in the diabetic animals $5.18 \pm 0.11 \%$ (mean \pm SEM), compared with control animals, $4.67 \pm 0.13 \%(P<0.005)$. In contrast to the cerebrum and cerebellum, the protein content was found to be decreased in the liver $(P<0.005)$ and in the placenta $(P<0.001)$ of the diabetic animals, either in total content, per g of tissue, or per DNA.

In order to search for any relationship between body weight and growth of each organ, regressions were calculated and compared between the two groups.

The cerebrum, liver, and placenta weights correlated linearly with fetal weights, within each group (Fig. 1). Furthermore, the weight of the cerebrum varied with fetal weight according to the same linear regression equation (same slope, same elevation) in the diabetic and control animals. No correlation was observed between the cerebellum weight and fetal weight within each group. In regard to liver and placenta weight, the slope of their regression line with fetal weight was higher $(P<0.025$ and $<$ $0.05)$ in the diabetic animals compared to controls. This suggests that in the fetuses of diabetic animals, liver and placenta weights in relation to fetal weights increase at a faster rate as fetal weights rise. The smallest fetus of the diabetic group $(43 \mathrm{~g})$ had a placental weight of $5.87 \mathrm{~g}$, which differentiated it from the others of its group (Fig. $1 D$ ). Therefore, this fetus has been excluded from the analysis of the correlation between placental and fetal weight, and it will be discussed separately.

\section{DISCUSSION}

This study raises important issues with regard to fetal brain development during diabetic pregnancy. Whereas decreased fetal brain weights have been previously reported in diabetic pregnancy $(10,14)$, our results do not support these findings. Fetal cerebrum and cerebellum weights were found to be similar in diabetic and control guinea pigs, when comparisons were made at the same time of gestation, in animals with similar fetal weights. It is well known that diabetes may affect fetal growth and predisposes to prematurity. Therefore, it is essential to consider these two variables together, especially since maturity and nutritional status affect fetal brain development $(3,6,12$, 29,30). Accordingly, positive correlations were found in this study between cerebrum weights and fetal weights over a wide range of fetal weight values. Furthermore, the linear regression between these two variables was identical in the diabetic and control animals, clearly indicating that brain growth was not
Table 2. Fetal values for the cerebrum*

\begin{tabular}{lllc}
\hline & $\begin{array}{c}\text { Control } \\
(n=22)\end{array}$ & $\begin{array}{l}\text { Diabetic } \\
(n=33)\end{array}$ & \multicolumn{1}{c}{$P$} \\
\hline Weight $(\mathrm{g})$ & $2.26 \pm 0.03$ & $2.22 \pm 0.02$ & $\mathrm{NS}$ \\
DNA (mg) & $3.01 \pm 0.26$ & $5.47 \pm 0.52$ & $<0.001$ \\
DNA/g & $1.34 \pm 0.12$ & $2.46 \pm 0.23$ & $<0.001$ \\
Protein (m) & $62.2 \pm 5.8$ & $75.3 \pm 4.6$ & $\mathrm{NS}$ \\
Protein/g & $27.6 \pm 2.5$ & $34.1 \pm 2.2$ & $\mathrm{NS}$ \\
Protein/DNA & $24.2 \pm 3.6$ & $17.2 \pm 1.8$ & $\mathrm{NS}$ \\
Cerebroside-sulfatide (mg) & $7.94 \pm 1.41$ & $8.32 \pm 1.15$ & $\mathrm{NS}$ \\
Cerebroside-sulfatide/g & $3.46 \pm 0.59$ & $3.71 \pm 0.50$ & $\mathrm{NS}$ \\
\hline
\end{tabular}

* Values are mean \pm SEM. NS, not significant.

Table 3. Fetal values for the cerebellum*

\begin{tabular}{lccc}
\hline & $\begin{array}{c}\text { Control } \\
(n=22)\end{array}$ & $\begin{array}{c}\text { Diabetic } \\
(n=33)\end{array}$ & $P$ \\
\hline Weight $(\mathrm{g})$ & $0.25 \pm 0.01$ & $0.22 \pm 0.01$ & $\mathrm{NS}$ \\
DNA (mg) & $1.69 \pm 0.21$ & $3.85 \pm 0.18$ & $<0.001$ \\
DNA/g & $7.15 \pm 0.84$ & $18.77 \pm 1.10$ & $<0.001$ \\
Protein (mg) & $8.70 \pm 0.83$ & $9.53 \pm 0.66$ & $\mathrm{NS}$ \\
Protein/g & $35.5 \pm 3.5$ & $48.5 \pm 4.5$ & $<0.05$ \\
Protein/DNA & $6.26 \pm 1.04$ & $2.70 \pm 0.24$ & $<0.001$ \\
Cerebroside-sulfatide (mg) & $2.39 \pm 0.32$ & $3.73 \pm 0.65$ & $\mathrm{NS}$ \\
Cerebroside-sulfatide/g & $9.71 \pm 1.28$ & $18.0 \pm 3.0$ & $<0.05$ \\
\hline
\end{tabular}

$*$ Values are mean \pm SEM. NS, not significant.

Table 4. Fetal values for the liver and the placenta*

\begin{tabular}{lccc}
\hline & $\begin{array}{c}\text { Control } \\
(n=22)\end{array}$ & $\begin{array}{c}\text { Diabetic } \\
(n=33)\end{array}$ & $P$ \\
\hline Liver & & & \\
Weight (g) & $3.49 \pm 0.14$ & $3.79 \pm 0.14$ & $\mathrm{NS}$ \\
DNA (mg) & $19.2 \pm 1.7$ & $22.0 \pm 1.0$ & $\mathrm{NS}$ \\
DNA/g & $5.40 \pm 0.32$ & $5.99 \pm 0.29$ & $\mathrm{NS}$ \\
Protein (mg) & $342 \pm 53$ & $207 \pm 16$ & $<0.01$ \\
Protein/g & $101 \pm 17$ & $55.5 \pm 3.8$ & $<0.005$ \\
Protein/DNA & $16.5 \pm 2.7$ & $9.62 \pm 0.64$ & $<0.005$ \\
Placenta & & & \\
Weight (g) & $4.17 \pm 0.16$ & $4.45 \pm 0.16$ & $\mathrm{NS}$ \\
DNA (mg) & $13.1 \pm 0.9$ & $16.2 \pm 1.2$ & $\mathrm{NS}$ \\
DNA/g & $3.17 \pm 0.21$ & $3.63 \pm 0.23$ & $\mathrm{NS}$ \\
Protein (mg) & $221 \pm 17$ & $149 \pm 9$ & $<0.001$ \\
Protein/g & $53.6 \pm 3.9$ & $33.5 \pm 1.8$ & $<0.001$ \\
Protein/DNA & $18.1 \pm 1.6$ & $9.8 \pm 0.6$ & $<0.001$ \\
\hline
\end{tabular}

$*$ Values are mean \pm SEM. NS, not significant.

affected by diabetes once fetal weight and gestational age were taken into account.

However, higher liver and placenta weights, in relation to fetal weight changes, were found in diabetic animals. This finding corroborates other studies which reported an increased placental/ fetal weight ratio in diabetic women and in streptozotocin-treated rats $(17,28)$. In this regard, the smallest of all the fetuses came from the diabetic group and it had a high placental weight. This fetus may have been growth-retarded secondary to maternal 

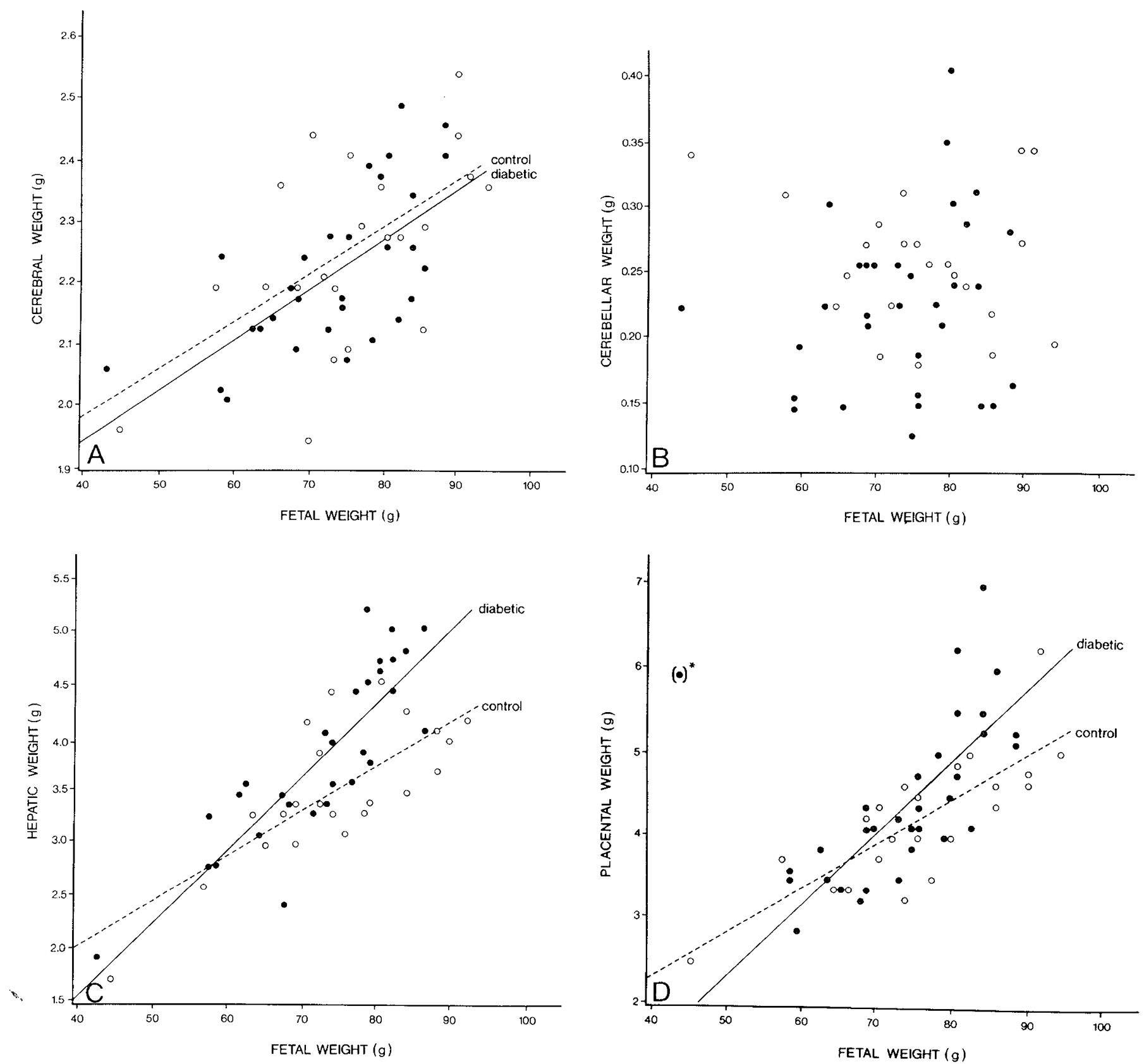

Fig. 1. Linear regressions between fetal parameters and fetal weight in control $(O)$ and diabetic $(\bullet)$ guinea pigs. A, Cerebral weight versus fetal weight in controls, $y=1.66+0.008 x \pm 0.13(\mathrm{SE}), r=0.58(P<0.005)$ and in diabetics, $y=1.60+0.008 x \pm 0.1, r=0.65(P<0.001)$; regression lines are identical $(P>0.05)$. B. Cerebellar weight versus fetal weight in controls, $y=0.32-0.0009 x \pm 0.05, r=-0.22(P>0.05)$ and in diabetics, $y=0.13+0.0012 x \pm 0.063, r=0.19(P>0.05)$; regression lines are not drawn, because they are not significant. $C$, Hepatic weight versus fetal weight in controls, $y=0.28+0.043 x \pm 0.45, r=0.74(P<0.001)$ and in diabetics, $y=-1.31+0.07 x \pm 0.43, r=0.85(P<0.001)$; slopes of the regression lines are different $(P<0.025)$. $D$, Placental weight versus fetal weight in controls, $y=0.24+0.053 x \pm 0.47, r=0.79(P<0.001)$ and in diabetics, $y=-1.99+0.087 x \pm 0.58, r=0.79(P<0.001)$; slopes of the regression lines are different $(P<0.05){ }^{*}$, Diabetic value excluded for the calculation of the regression equation.

diabetes, and not to a placental mass deficiency. This would corroborate Pitkin's findings (17) who reported high placental/ fetal weight ratio in growth-retarded fetuses of severely diabetic rats. The weight increase in different organs of newborns of diabetic mothers has also been associated by some authors with increased glycogen content $(16,17,24)$.

In contrast to the cerebrum, no correlation was observed in diabetic or control animals between cerebellum weight and fetal weight, despite a wide range of fetal weight values. This is inconsistent with previous studies, which showed in the human and the guinea pig that cerebellum weight was more affected than the cerebrum by changes in fetal weight $(5,6)$. In these studies, although the DNA content was found to be lower in the cerebellum than in the cerebrum of human fetuses with growth retardation, it was equally decreased in both parts of the brain, in the guinea pig model $(5,6)$. This may be due to differences in brain maturation between species. For instance, approximately $25 \%$ of the adult brain weight is present at birth in the human, compared with $70 \%$ in the guinea pig (5). In addition, the total brain DNA content at birth represents $75 \%$ of the adult value in the human, compared with $100 \%$ in the guinea pig (5). Furthermore, different regions of the brain may have different rates of maturation in utero, and the patterns may be different from one species to another. For example, in the human, the cerebrum matures at a faster rate prenatally than does the cerebellum, whereas at birth, both cerebrum and cerebellum have achieved 
the same maturity in the guinea pig $(5,9)$. Therefore, it is possible that such conditions as fetal malnutrition or diabetic pregnancy may have different effects upon brain development depending upon the species under study. Despite these differences between the human and the guinea pig, these two species still offer more similarities with regard to fetal brain development, than other animals such as mouse, rat and rabbit $(1,5,8,9)$.

One of the most unexpected findings of this study was the increased DNA content of the cerebrum and the cerebellum in diabetic animals. Organ DNA content is a reliable index of its cell number, without providing any information concerning the cell types. Many growth factors have been recently identified. Among them, the nerve growth factor, which has been implicated in fetal nervous tissue development, presents many structural homologies with proinsulin (21). Since infants of diabetic mothers and fetuses of streptozotocin-treated rats have high insulin blood levels $(16,17)$, it is possible that insulin, or other factors, in some way promotes brain cell number in these fetuses. Any further research to clarify this hypothesis in the guinea pig model will have to take into consideration the particulars of guinea pig insulin which has been reported to be different from porcine, bovine, or human insulin in terms of physical and biological properties $(32,33)$.

The decreased protein content found in the liver and the placenta might be related to the impaired placental transfer of essential amino acids previously reported in diabetic pregnancies (23). However, the brain seems in some way to be spared from the protein deprivation observed in the liver and placenta. In fact, the protein content per $g$ of cerebellum was actually increased in diabetic animals. The extent to which fetal amino acid supply or protein synthesis in the brain is affected by diabetic pregnancy remains to be established.

Fetal malnutrition has been associated with decreased myelin content in the brain $(5,6,12)$. In this study, this effect has not been observed in diabetic animals. On the contrary, cerebrosidesulfatide concentrations were increased in the cerebellum. Proteins represent $30 \%$ of the myelin composition (19). The fact that both are increased in the fetal cerebellum, per $g$ of tissue, in diabetic animals, may not be coincidental. However, protein content was not increased to the same extent as cellularity in the cerebellum, as suggested by the decreased protein/DNA ratio.

It remains difficult to ascertain whether these observations made on fetal brain development in guinea pigs rendered diabetic with streptozotocin apply to the human situation. For instance, we were not able, in the present study, to demonstrate an increased fetal weight in the diabetic group compared to the control one, which may be due to the high range in fetal weight values observed within each litter in both groups. In addition this study does not investigate the causes or clinical implications of the effects of diabetes upon fetal brain development. These are important issues to evaluate, since in the human as in the guinea pig, the fetal brain is much more mature than any other organ at birth. It is always a possibility that any adverse condition affecting brain development during pregnancy may have long term postnatal effects.

\section{REFERENCES AND NOTES}

1. Agrawal HC, Davis JM, Himwich WA 1968 Changes in some free amino acids of guinea pig brain during postnatal ontology. J Neurochem 15:529

2. Avery GB 1981 Neonatology, Pathophysiology and Management of the Newborn, 2nd ed. Philadelphia, JB Lippincott Company, p 289

3. Brasel JA Winick M 1972 Maternal nutrition and prenatal growth. Experimental studies of effects of maternal undernutrition on fetal and placental growth. Arch Dis Child 47:479
4. Brosky G, Logothetopoulos $\int 1969$ Steptozotocin diabetes in the mouse and guinea pig. Diabetes 18:606

5. Chase HP Dabiere CS, Welch NN O'Brien D 1971 Intra-uterine undernutrition and brain development. Pediatrics 47:491

6. Chase HP, Welch NN, Dabiere CS, Vasan NS, Butterfield LJ 1972 Alterations in human brain biochemistry following intrauterine growth retardation. Pediatrics 50:403

7. Davison AN, Wolfaard G 1963 Quantitative analysis of lipids by TLC. Biochem J 29:1P

8. Dobbing J, Sands J 1970 Growth and development of the brain and spinal cord of the guinea pig. Brain Res 17:115

9. Dobbing J, Sands J 1973 Quantitative growth and development of human brain. Arch Dis Child 48:757

10. Driscoll SG, Benirschke K, Curtis GW 1960 Neonatal deaths among infants of diabetic mothers. Am J Dis Child 100:818

11. Fanaroff AA, Martin RJ (eds): Behrman's Neonatal-Perinatal Medicine, 1983 Diseases of the Fetus and Infant, 3rd ed. St-Louis, CV Mosby Company, p 854

12. Fishman MA, Prensky AL, Dodge PR 1969 Low content of cerebral lipids in infants suffering from malnutrition. Nature 221:552

13. Folch J, Lees M, Stanley GHS 1957 A simple method for the isolation and purification of total lipids from animal tissues. J Biol Chem 226:497

14. Gruenwald $P 1966$ Growth of the human fetus. Abnormal growth in twins and infants of mothers with diabetes, hypertension, or isoimmunization. Am Obstet Gynecol 94:1120

15. Losert W, Rilke A, Loge O, Richter KD 1971 Comparative biochemical studies on the diabetogenic action of streptozotocin in mice, rats, Chinese hamsters and guinea pigs. Arzneim Forsch 21:1643

16. Pedersen J 1977 The Pregnant Diabetic and Her Newborn, 2nd ed. Baltimore, The Williams and Wilkins Company

17. Pitkin RM, Van Orden DE 1974 Fetal effects of maternal streptozotocindiabetes. Endocrinology 94:1247

18. Radin NS, Lasin FB, Brown JR 1955 Determination of cerebrosides. J Bio Chem 217:789

19. Reinis S, Goldman JM 1980 The Development of the Brain, Biological and Functional Perspectives, Chap 12, Myelin and Myelinization. Springfield, IL, Charles C Thomas, p 177

20. Richter KD, Loge O, Losert W 1971 Comparative morphological studies on the diabetogenic activity of streptozotocin in rats, Chinese hamsters, guinea pigs and rabbits. Arzneim Forsch 21:1654

21. Sabesan MN 1980 Secondary structural and "active site" homologies between nerve growth and insulin. J Theor Biol 83:469

22. Saintonge J, Côté R 1983 Placental transfer of amino acid and glucose analogs in relation to maternal glucose tolerance. In: Stern L, Bard H, Früs-Hansen B, (eds): Intensive Care in the Newborn. New York, Masson Publishing, p. 1

23. Saintonge J,Côté $\mathrm{R} 1983$ Intrauterine growth retardation and diabetic pregnancy: two types of fetal malnutrition. Am J Obstet Gynecol 146:194

24. Schaffer AJ, Avery ME 1977 Diseases of the Newborn, 4th ed. Philadelphia WB Saunders Company, p 80

25. Schneider WC 1957 Determination of nucleic acids in tissues by pentose. Methods Enzymol 3:680

26. Spector T 1978 Refinement of the Coomassie blue method of protein quantitation. A simple and linear spectrophotometric assay for 0.5 to $50 \mu \mathrm{g}$ of protein. Anal Biochem 86:142

27. Vaughan VC, McKay RJ, Behrman RE (eds): 1979 Nelson Textbook of Pediatrics, 11 th ed. Philadelphia, WB Saunders Company, p 465

28. Vejtorp M. Pedersen J, Klebbe JG, Lund E 1977 Low concentration of plasma amino acids in newborn babies of diabetic mothers. Acta Paediatr Scand $66: 53$

29. Winick M 1971 Cellular growth during early malnurition. Pediatric 47:969

30. Zamenhof S, Van Marthens E 1974 Study of factors influencing prenatal brain development. Mol Cell Biochem 4:157

31. Zar JH 1974 In: McElroy WD, Swanson CP (eds): Biostatistical Analysis, Chap 17. Englewood Cliffs, NJ, Prentice-Hall Inc, p 228

32. Zimmerman AE, Yip CC 1974 Guinea pig insulin. I. Purification and physical properties. J Biol Chem 249:4021

33. Zimmerman AE, Moule ML, Yip CC 1974 Guinea pig insulin. II. Biological activity. J Biol Chem 249:4026

34. This research was supported by Medical Research Council of Canada Grant MA-6456. These data were presented in part at the International Neonatal Intensive Care Collegium, Spetses, Greece, June 13-17, 1983

35. Requests for reprints should be addressed to: Jacques Saintonge, M.D., Department of Pediatrics, Maisonneuve-Rosemont Hospital, 5415 l'Assomption Boulevard, Montreal, Quebec HIT 2M4.

36. The authors are grateful to Mr. François Rochefort of Maisonneuve-Rosemont Hospital and Mr. Richard Tanguay of the Human Growth Research Center, University of Montreal, for reviewing the statistical analysis of data.

37. Received for publication April 20, 1983.

38. Accepted for publication September 20, 1983. 